\title{
DEVELOPING E-LEARNING MEDIA WITH THE CONTIGUITY PRINCIPLE FOR THE SUBJECT OF AUTOCAD
}

\author{
${ }^{\mathbf{1}}$ Nur Hidayat, ${ }^{\mathbf{2}}$ Samsul Hadi, ${ }^{\mathbf{3}}$ Abd. Basith, ${ }^{4}$ Suwandi \\ 1,2 Faculty of Engineering, Universitas Negeri Yogyakarta, Indonesia \\ ${ }^{3}$ Central China Normal University, China \\ ${ }^{4}$ Peneliti Pusat Penelitian Kebijakan Pendidikan dan Kebudayaan, Indonesia \\ E-mail: nurhidayat@uny.ac.id
}

\begin{abstract}
Technological advances have made possible to reduce limitation of space and time in learning. Students can interact with teachers and other students indirectly without face to face meetings through e-learning media. To create effective e-learning media, factors to be mainly considered are multimedia learning principles, one of which is contiguity. Thus, this study was aimed at developing e-learning media with the contiguity principle and examining its quality. The media were tested for measuring its effectiveness by statistically analyzing the differences in students' learning achievement and motivation. This study was research and development using quasi experimental techniques whose subject is Vocational High School also known as Sekolah Menengah Kejuruan Negeri 2 Yogyakarta. The result of this study was e-learning media with the contiguity principle. The feasibility evaluation showed that the product had good quality in the aspects of media and materials. The effectiveness testing showed insignificant differences in learning achievement and motivation between the students using e-learning media with the contiguity principle and without the contiguity principle with the scores of 0.325 and 0.873 respectively.
\end{abstract}

Keywords: achievement, contiguity, e-learning, motivation

\section{INTRODUCTION}

The development of information and communication technology is very influential in various fields, mainly in education. Learning media is one of the learning aspects that closely related to educational technology. Both of educators and students use technology as learning media without which the learning is almost impossible. It happens because the learning media is an intermediary message from the source of information to the recipient of information. Learning media is one component of communication because learning is a communication process. Various types of media that can be used to convey messages in a learning activity can be incorporated into the learning medium. The learning process as a communication process will not be able to take place optimally without the media. The importance of the instructional media needs to be balanced with the proper use of the media for achieving maximum results. The role of the media as a messenger in the learning process adapted from Heinich et al (2002) is presented in Figure 1

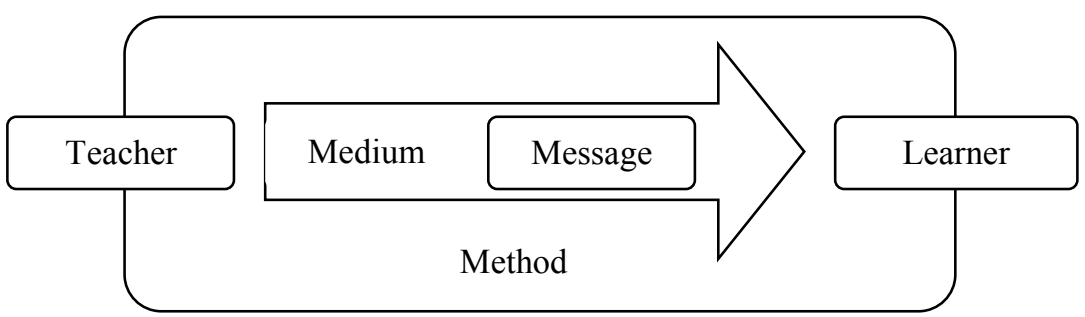

Figure 1. The Role of Media

Many problems arise in the learning process. One of the reasons is that the meaning of a learning process is still often associated with the meeting of educators (teachers) and 
students directly. Therefore, schools are still considered as the only place of education. Many people argue that teachers can provide knowledge to students only in schools. Today, that statement is no longer used. The direct interaction between teachers and students can be facilitated by the existence of ICT especially computers and internet networks.

Learning is no longer limited by space and time using Information and Communication Technology (ICT). Teachers and students do not only interact with face-to-face learning. The learning process can take place in the same space but different times, different spaces but the same time, and even in different spaces and times. Utilization of ICT which is more flexible and can reduce the limitations of space and time is expected to facilitate the learning process maximally.

ICT cannot be separated from educational activities. The development of ICT has directed the learning process more broad and flexible. In the utilization of ICT, elearning is an internet application that can act as media between teachers and students in a lesson. The learning process that occurs in elearning does not require a face to face meeting between teachers and students. Limitations of space and time in learning activities can be overcome by E-Learning. Students can interact with teachers or other students directly or indirectly.

Chaeruman (2008) states that e-learning is a learning that utilizes or implements ICT. Implementing e-learning will enable active, constructive, collaborative, enthusiastic, dialogical, contextual, reflective, multisensory learning, and practice high-level thinking skills. Meanwhile, Naidu (2006) has a similar concept of e-learning as an electronic media which use information networks for communication technologies in learning-

E-Learning philosophy can be explained as follows (1) media delivery of information and communication in education that now has shifted and developed online, (2) presents a set of tools and technologies that can add values of the learning to cope with the challenges of globalization era, and (3) does not replace the conventional learning model, but strengthens the conventional learning model through the development of information and communication technology.

Henderson (2003) states that the delivery of materials on e-learning is divided into three basic methods, namely: Synchronous Learning where learning activities are conducted by teachers and students in the same place and time and the same time but different places; Self-Directed Learning where learning activities are conducted by means of students accessing and learning their own materials without any interaction with teachers or other students; Asynchronous (Collaborative) Learning which is a combination of the two methods above. Teachers and students in different times and places are able to do learning activity wherever and whenever. It can be concluded that elearning is a learning by utilizing electronic equipment including network information and communication technology as the media.

Basically, e-learning materials have not to be distributed online but it can be distributed offline using any data storage media. However, e-learning specifically is defined as learning that utilizes computer technology and Internet network. E-learning model allows students to learn through computers without having to meet with teachers directly. E-learning is also often understood as a form of web-based learning that can be accessed via internet or intranet (local network). In this study, researchers used the Synchronous learning approach as the basic method of delivering the material. Implementation of learning activities done by way of teachers and students are at the same time and space so as not to be separated from the learning in general (blended learning). Learning is done in the classroom with elearning using intranet (local) network.

The use of electronic media in learning cannot be separated from learning in general. However, there is something typical of learning using computers and the internet, namely the 
ability of students to be able to learn independently. This meets the ideal learning model where the teacher is no longer a learning center but plays a role as a facilitator. The role of students as the main actors in learning (student-centered learning) provides more opportunities for students to be more active, although it is still under the direction and supervision of the teachers.

In the current learning process, the utilization of e-learning, especially in Vocational High Schools (VHS) also known as Sekolah Menegah Kejuruan (SMK) is still poor. This is indicated by the lack of willingness and the ability of the teachers in using e-learning. In addition, the teachers do not give attention to the factors that are very influential on the use of learning media especially text, images, and animation. The most influential factors are the principles of multimedia learning.

SMK Negeri 2 Yogyakarta is one of VHS that does not use E-learning maximally. The school already has adequate computer facilities and internet networking. However, currently, the internet facility is not used maximally for learning. The problems occur in almost all training subject including AutoCAD. ICT is not used optimally as instructional media thus it does not increase the motivation of the students thus it certainly cannot be maximal in improving the quality of learning process. In addition, in the development of instructional media, the teachers also pay less attention to the influence of the instructional multimedia principles including the Contiguity principle which is the closeness between texts and images.

Clark \& Mayer (2008) write some principles of e-learning media for the effective learning process. The principles consist of (1) the principle of multimedia (the use of words and images rather than words only), (2) contiguity, (3) the modality (the use of words in narration rather than just words), (4) redundancy (visual explanation with voice or text description, not for both), (5) coherency (6) personalization (using actual style of conversation and style), and (7) segmenting and pertaining (managing complexity by dividing learning in sections). This study focuses on one of the six principles, namely the principle of contiguity (closeness between text and graphics).

Mayer (2009) explains that the contiguity principle refers to the closeness of the arrangement of texts and images on the screen. Text and images are presented near each other in the same place or time. Development of elearning media by applying the principle of contiguity is based on the consideration that students will more quickly and easily receive learning materials. Mayer distinguishes the principle of contiguity into two, namely spatial contiguity and temporal contiguity.

In addition, Mayer (2009) claims that students do not have to use memory (cognitive) when texts and images are presented close together in one place (both book and monitor pages). This can happen because students do not need a lot of memory to visually seek information. Students will more easily capture and store information simultaneously. If texts and images are not presented near each other in one place or time, students will need memories to visually seek information. This will most likely cause the student to be unable to capture and store information simultaneously. Therefore it can be concluded that the contiguity principle emphasizes on the closeness of the texts and related images. The closeness of the texts and images can be either closeness of space or proximity time. This research and development use the principles of contiguity, both spatial contiguity, and temporal contiguity.

From the background of the above problems, this study is focused on the development of e-learning as a medium of learning, especially on content using the contiguity principle (closeness between the text and images). The learning materials were obtained from the curriculum thus this study did not interfere with the implementation of the curriculum that the school had implemented. 
The material is about how to create 3 Dimensional object images (3D) using AutoCAD. There is a difference between elearning and conventional learning where all the e-learning materials can be fully controlled by the teacher so that the teacher can make the necessary adjustments in real time. On that basis, it is developed media that can improve learning achievement and provide the learning motivation for the students.

\section{METHOD}

This study was conducted by developing a learning product and testing its effectiveness. Borg \& Gall (1983) explain that research and development is a process used to develop or validate the products used in learning. Research and development are carried out continuously: research related to product development, product development based on the research, field trials organized like real learning, and revising products to correct the deficiencies found in the field test. Meanwhile, Alessi \& Trollip (2001) explain that the research and development model is emphasized on the flexibility aspect so that developers can obtain results in accordance with the needs and style of work, especially in designing and developing multimedia learning.

Stages in the development model offered by Alessi \& Trollip (2001) are (1) standards which is a basis for good product development, (2) ongoing evaluation, and (3) Careful project management from start to finish. In addition to these three attributes, there are also three stages in the Alessi \& Trollip (2001) development model used in research and development, namely (1) Planning, (2) Designing, (3) Developing.

This study is categorized as research and development started from the initial study of problems that occur in the learning as well as the solution. In this study, it is developed elearning media by applying the contiguity principle in the media content. This study refers to the predetermined criteria based on the adaptation of the Alessi \& Trollip (2001) development model. Developers adapt both in planning, design, and development on the basis of development needs and learning characteristics. Figure 2 presents an outline of the e-learning development model adapted from Alessi \& Trollip (2001).

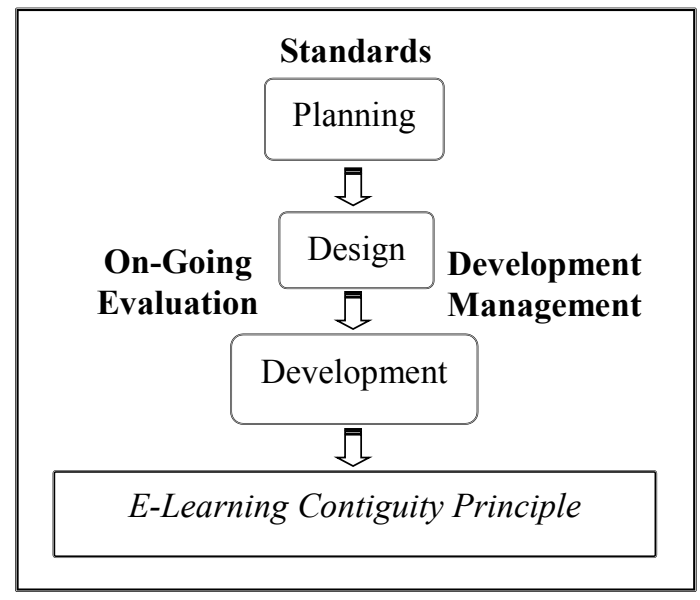

Figure 2. E-Learning Development Mode

This research and development activity refers to the criteria set by the developer including product standard, management, process, and evaluation. The product standard specified is an e-learning material for VHS in the form of a Learning Management System (LMS). E-learning presents learning materials for AutoCAD training for grade $\mathrm{XI}$ in the Department of Building Engineering. Development management standards are based 
on regulating the components of the activities systematically required to produce product development. Components involved in the development activities include human (researchers, media experts, material experts, teachers, and students), curriculum (syllabus and lesson plans), and technology (computer and internet). Standard development processes include the planning, design, and development phases. Each of these stages is arranged systematically. The development process is made operational procedure at each stage. The evaluation standard set by the researcher is the e-learning product evaluation standard that includes formative evaluation and summative evaluation. Formative evaluation in the form of (1) ongoing evaluation conducted by researchers to students during development, (2) an alpha test conducted by media experts and material experts. This evaluation will determine the quality of the product. Eligibility qualities are achieved if they have a good category, and (3) a beta test conducted by teachers and students whose function is similar to an alpha test. Eligibility qualities are achieved if they have a good category. Meanwhile, summative evaluation or e-learning validation is done in a real learning. This evaluation is conducted to assess the effectiveness of the product in learning. In this study, it does not fully use elearning but still uses the face to face explanation (blended learning). Application of blended learning is proved to be able to improve the students' learning outcomes, both cognitive, affective, and psychomotor (Nurmayani et al, 2017). In addition, blended learning is also an appropriate learning model used with various supporting factors and inhibiting learning (Prasetyo et al., 2016).

Field trials in this study were conducted through quasi-experiments. Samad (2009) explains that there are several quasiexperimental research designs or quasiexperiments, one of which is pretest-posttest, non-equivalent control group design. The design of this study did not differ much with other research designs (posttest only). This design is distinguished by providing a pretest before the treatment. The pretest examines the degree of group equality to be considered as well. The pretest in the design of this study can also be used for statistical control and can be used to see the effect of treatment on the gain score. The implementation of validation test or field trials is done by quasi-experiment because the subject naturally formed in a group of intact that is a group of students in one class. In addition, in this research and development, the variable control related to the research subjects cannot be done completely so the research must be done by using intact group. It can be said that quasi-experimental research uses all subjects in study groups to be treated (treatment), rather than using randomly picked subjects.

The field trials used one control group and one experimental group. The control group was only taught using e-learning while the experimental group is taught using e-learning based on contiguity principles. The group used is an intact group that is a class group. The field test model in this study is presented in Table 1.

Table 1. The Field Test Model

\begin{tabular}{|c|c|c|c|c|}
\hline No & $\begin{array}{l}\text { Intact } \\
\text { Group }\end{array}$ & Pretest & Experimental Variable & Posttest \\
\hline 1 & Class 1 & $\mathrm{O}_{1}$ & Control & $\mathrm{O}_{2}$ \\
\hline 2 & Class 2 & $\mathrm{O}_{3}$ & Experiment & $\mathrm{O}_{4}$ \\
\hline
\end{tabular}

The developed product is tested first before being utilized in learning activities. Testing is done to get input from both material and media aspects so that it can be tested both theoretically and empirically. The data obtained from the trial is used to improve the product. Figure 3 shows the product test design in this study. 


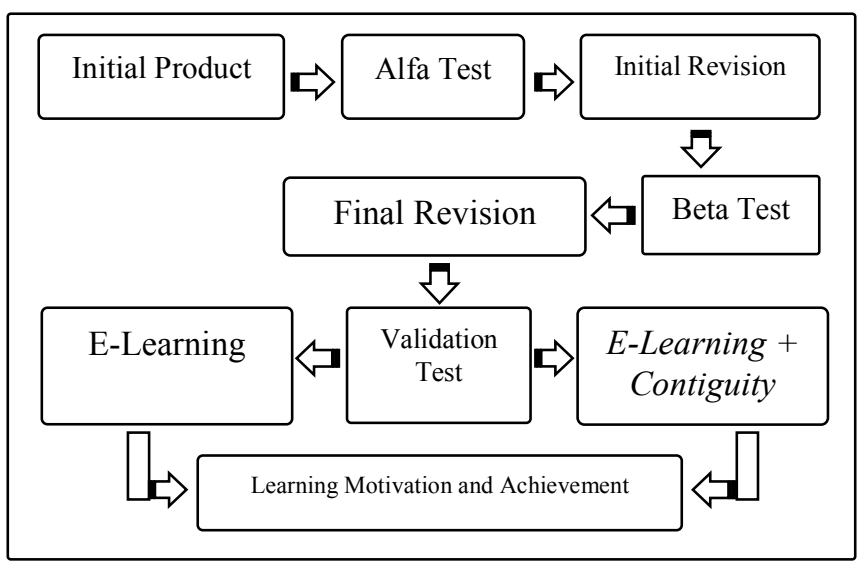

Figure 3. Product Trial Design

The trial design includes three stagesnamely an alpha test, a beta test, and implementation (field trial). The trial with an alpha test is a formal internal test. This trial involves the developer along with a material expert and a media expert. The purpose of this test is to identify and reduce the product problems, both procedures, and compliance with objectives. The problems encountered are then revised so that the product is ready to be used by the students during the next test (beta test).

A beta test is a formal test after the alpha test. It is conducted by teachers and students. In this trial, the learning in-setting is identical with real learning. The results of the beta test were used in the final revision. The test was applied to two classes as the trial subject, one class as the treatment group (experiment) and one class as the control group

The product trial is intended to obtain the data used as the basis for analyzing the quality of the feasibility of the learning media. The type of data used in this study was quantitative data equipped with qualitative data and document process data. Quantitative data for product feasibility were derived from alpha and beta tests. Learning achievement data were obtained from the score of the students, while the motivation data were obtained from the questionnaire administrated to the students. Furthermore, quantitative data was then converted into qualitative data so that it can be read the level of eligibility and motivation using learning media.

Instruments are structured on the basis of media quality indicators (Alessi \& Trollip, 2001). The grid of the feasibility instrument used is divided into two aspects: material feasibility (learning scope, additional information, user attitudes, pedagogy, and additional material) and media feasibility (information, user relationships with programs, navigation, pedagogy, invisible features, program reliability, additional materials)

In addition to the instruments that determine the feasibility quality of the product, there are also instruments used to determine the improvement in the students' learning motivation (Suratno, 2010). Aspects to be assessed consist of internal motivation (desire for success, motivation and needs to learn, expectations and aspirations) and external motivation (awards in learning, the influence of the environment in learning, and interesting activities in learning)

The techniques of determining the validity and reliability of this instrument include determining the validity of evaluation instruments by media experts, material experts, teachers, students, and motivation instruments. In addition, the instrument validity testing of the test items of the subject of AutoCAD is also done by experts. Prior to use, the instrument must satisfy the logical validity obtained from discussions with mentors and involving experts 
(expert judgment). The main idea contained in reliability is the extent to which the results of a measurement can be trusted (Azwar, 2008).

Meanwhile, to meet the requirement that the data be feasible to be analyzed then a prerequisite test, the normality test (to prove that the normally distributed data using the Kolmogorov Smirnov normality test) and the homogeneity test (to prove that the data came from the same or homogeneous variant using Levene Statistic). Meanwhile, the significant difference in learning achievement between the experimental group and the control group was conducted using a T-test. In this analysis testing, $\mathrm{H} 0$ : there is no significant difference in learning achievement between the experimental group and the control group against H1: there is a significant difference in learning achievement between the experimental and the control groups. In addition to the test for the significance of the difference in learning achievement gain, the T-test was also conducted to determine the significance of experimental group gain gap with the control group.

\section{RESULTS AND DISCUSSION}

Learning with e-learning media using the principle of contiguity can be used as one of the media in learning. The medium was developed in three stages, namely planning, design, and development. The planning stage is a preliminary activity before determining the concept of product development design. Steps taken at this stage include: determining the scope of the material, identifying the characteristics of students, limiting Basic Competence, planning learning and support resources, as well as interviews about the design concepts. In the design phase, the researcher performs several steps including developing the initial idea, describing the program, creating a flowchart, and making a storyboard. The initial idea of e-learning development using the principle of contiguity comes from a network learning, both online and offline. The material is presented in the form of PowerPoint, Word, PDF, or other software that uses the principle of contiguity. At the stage of development, researchers assemble the parts that have been produced into a product. Steps in this development include: choose and manage the application software Learning Management System that is Moodle as needed, prepare the material, and upload the material with other additional information. Software installed on the laptop for later adjusted as needed. This is done because the internet network in the school has not been stable so that if it is used, it will interfere the study. Settings are done using the browser, in this case, researchers use Mozilla Firefox. Researchers give the name of this elearning media Be Be Best E-Learning. The address to set up Moodle in the researcher's laptop is http: // localhost / moodle /. In the implementation of the school laboratory, the address is replaced using Internet Protocol (IP) admin computer in which case the teacher's computer is http://192.168.0.37/moodle/.

In the implementation of planning, design, development, and validation of learning product on alpha test, researchers get various inputs from material experts, media experts, teachers, and students. The inputs are used as consideration for revision. Expert validation by the experts in the next stage is done after the researchers made a revision according to expert advice. The final test is the second validation done by the researcher. Revisions in this validation are based on input from teachers and students during beta test validation. These experimental and development trials include formative tests (alpha and beta tests) and summative tests performed with real learning. Formative tests conducted to determine the quality of product feasibility, while the summative test conducted to obtain data achievement and motivation to learn.

In the alpha test, based on media expert's assessment of media aspect indicators, the overall average score of 4.00 was obtained and included in a good category. Therefore, if the development product is viewed from the aspect 
of the media it can be declared feasible to be tested at a later stage. It is also supported by comments and temporary conclusions by media experts whose respective statements are testable and appropriate for field trials without revision. Nevertheless, researchers continue to make necessary improvements. Meanwhile, the assessment of material experts on the material aspect indicators showed that the average score of 3.60 was obtained and included in the good category. Therefore, if the development product is viewed from the material side it can be declared feasible to be tested at a later stage. It is also supported by comments and conclusions by media experts who state that the product is eligible for field trials without revision.

Implementation of a beta test is in two classes that are the class using e-learning by using contiguity principle (experiment) and the class using e-learning without using contiguity principle (control). The trial subjects in the beta test were two teachers each for the experimental group and control group as well as the three students for the experimental group and the three students for the control group.

The beta test results conducted on teachers and students cover aspects of media and material aspects. The data comes from informal assessments, observations, and interviews. In the beta test, there is an increase in the gain value of each group. The increase for the experiment group and the control group are 6 points and 3.67 points respectively. From the above data, it can be concluded that there is an increase in the experimental group. In addition, there is also an increase in motivation gain for the experimental group and the control group which are 9.67 and 6.67 respectively. From the data it can be concluded that there is better improvement in the experimental group.

After the final revision, product development is used in real learning. The applications in the learning are differentiated for the experimental group and the control group. The data obtained in the experimental group is there is an increase in the gain from the average value of 2.00 and the gain of the average motivation of 1.23. Meanwhile, in the control class it is obtained an average gain value of 0.83 and the average gain value of motivation of 1.00 .

Data analysis of the planning stage is the product planning activity as needed, including determining the scope of the material, identifying the characteristics of students, limiting Basic Competence, planning the learning and supporting resources, and interviews about the design concepts. The selection of materials for the Competency Standards of building engineering drawing with computer software that meets the purpose of the study. The informal interviews conducted with students indicated that students have been accustomed to operate computers and access the internet. In addition, one of the Basic Competencies in the Competency Standards is to create a 3-dimensional object solid type image using AutoCAD is considered appropriate for this study. Learning AutoCAD using e-learning media is potential to improve the quality of learning and motivation of the students. The e-learning is designed in an attractive and easy way to be used in the learning process.

The data analysis at the design stage includes: developing the initial ideas, describing the program, creating a flowchart, and making a storyboard. The initial idea of elearning development using the contiguity principle comes from a network-based learning, both online and offline. The material is presented in a e-learning media. Students can actively learn to use the media without much disruption to the delivery of material. The product is developed according to the flowchart and the storyboard.

The design of the lesson has been assessed by the media expert and considered as an appropriate step for variation in learning. From the material aspect, both the content of the material and the presentation have been assessed and reviewed by the material experts 
thus the product design has been feasible to be developed. In addition, assessment of aspects of media and material aspects is also done by the teacher who give positive appreciation to the product development design.

Data analysis of development activities focuses on the preparation of the parts that have been produced at the design stage into the initial product. The development stages include: choosing a Learning Management System application software that is Moodle, prepare the material, organize Moodle as needed, and upload the material along with other additional information. Moodle software selection is an appropriate step, it is because the school has also prepared e-learning using Moodle as a medium of learning. The principle of contiguity is applied in the form of text and image proximity in accordance with the characteristics of 3 Solid Dimension type materials. Compliance can be seen with an explanation of the material that presents the image along with the description in the form of text. Images and tests layout can be arranged in such a way that it suits the type of media created. The materials are prepared and arranged to fit the lesson plan.
The media and material experts validation in the alpha test found that the media is feasible for the next trial. Improvements according to experts' suggestions have been performed so that the media can be proceed to the beta test. In addition, the beta test also concluded that the media was feasible to be used without further revision. The result of pretest analysis using T-test with the significance level of 0.05 proves that there is no significant difference in learning achievement between the experimental and control groups. The test has proven that the initial state of learning achievement of both groups is equal. These results can be used as the basis of studies using two groups (intact group) that is the experimental group and control group with the same initial learning achievement.

Meanwhile, the data analysis of learning achievement in the experimental group using Ttest proves a significant improvement of learning achievement between the pretest and the posttest. While in the control group, there is no significant improvement between pretests and posttests. The detailed results of data analysis are presented in Table 2 .

Tabel 2. Learning Achievement of the Experimental and the Control Groups

\begin{tabular}{ccccc} 
& \multicolumn{2}{c}{ Experimental Group } & \multicolumn{2}{c}{ Control Group } \\
& Pretest & Posttest & Pretest & Posttest \\
\hline Highest Score & 88.00 & 89.00 & 87.00 & 88.00 \\
Lowest Score & 76.00 & 76.00 & 76.00 & 76.00 \\
Mean & 81.10 & 83.10 & 80.90 & 81.73 \\
Median & 80.50 & 82.50 & 80.00 & 81.00 \\
Mode & 79.00 & 80.00 & 78.00 & 81.00 \\
Total & 2433 & 2493 & 2427 & 2452 \\
\hline
\end{tabular}

The data analysis revealed that there are increased gain values in both classes, but there is a higher and significant increase in the experimental class. In addition, these results prove that the use of the contiguity principle in learning media can improve learning achievement significantly. In testing the difference in gain of learning achievement between the experimental class and the control class, it obtained a score of 0.325 . It proves that there is no significant difference in learning achievement between the students treated using e-learning models with or without the contiguity principle. There is an increase in learning achievement in both classes but the improvement is not significant. When they are 
compared, the improvement of learning achievement in the experimental class is higher than the control class.

In the aspect of motivation, prerequisite test before the T-test is also done with a normality test and a homogeneity test. Based on the normality test using Kolmogorov-Smirnov, the data is normal. In addition, Based on the provision of homogeneity test, the data is homogeneous. The result of pretest analysis of learning motivation in the experimental and the control groups using a T-test with 0.05 significance level proves that there is no significant difference of learning motivation among the students. It indicates that the initial learning motivation of the experimental class and the control class is equivalent.

Meanwhile, the result of learning motivation analysis of the experimental and the control groups using T-test obtained a score of 0.873. It shows that there is no significant difference in learning motivation between the pretest and the posttest. In testing the difference of motivation in the experimental and control groups, it shows that there is an increase of gain value in both groups, but the increase of gain value is higher in the experimental group. Furthermore, the improvement of learning motivation in both classes when tested using Ttest is not significant. Table 3 presents the learning motivation Learning Motivation of the Experimental and the Control Groups.

Table 3. Learning Motivation of the Experimental and the Control Groups

\begin{tabular}{lcccc}
\hline & \multicolumn{2}{c}{ Experimental Group } & \multicolumn{2}{c}{ Control Group } \\
& Pre-test & Post-test & Pre-test & Post-test \\
\hline Highest Score & 140.00 & 141.00 & 131.00 & 131.00 \\
Lowest Score & 98.00 & 107.00 & 104.00 & 103.00 \\
Mean & 118.30 & 119.53 & 116.50 & 117.50 \\
Median & 117.00 & 118.00 & 116.00 & 118.00 \\
Mode & 108.00 & 116.00 & 106.00 & 118.00 \\
Total & 3549 & 3586 & 3495 & 3525 \\
\hline
\end{tabular}

\section{CONCLUSION}

This study provides a summary of the development process of e-learning media using the contiguity principle to deliver learning materials in the subject of AutoCAD. The product presents learning materials for Vocational High Schools students in grade XI of the Department of Building Engineering specifically for AutoCAD learning. The material is limited to Competency Standards of Drawing with computer software especially for Basic Competence of Creating 3 Solid Type Dimension Image Using AutoCAD. The developed product is considered feasible as leaning media based on media and materials experts' validation, as well as the assessment of teachers and students. There is a difference in achievement and learning motivation of the students treated using E-learning with and without the contiguity principle but it is insignificant. The developed product of elearning media using the contiguity principle can be used as one of solution for achieving maximal learning process especially in overcoming the limitations of space and time.

\section{REFERENCES}

Alessi, S. M. \& Trollip, S. R. 2001. Multimedia for Learning: Methods and Development $\left(3^{r d}\right.$ ed.). Massachusetts: Allyn and Bacon

Azwar, S. 2008. Reliabilitas dan Validitas. Yogyakarta: Pustaka Pelajar

Borg, W. R. \& Gall, M.D. 1983. Educational Research: An Introduction ( $4^{\text {th }}$ ed.). New York: Longman Inc.

Chaeruman, Uwes A. 2008. Mendorong Penerapan E-Learning di Sekolah. Jurnal Teknodik. 7.1, 26-32 
Clark, R.C. \& Mayer, R.E. 2008. E-Learning and the Science of Instruction: Proven Guidelines for Consumers and Designers of Multimedia Learning ( $2^{\text {nd }}$ ed.). San Francisco: Pfeiffer

Heinich, R., Molenda, M., Russell, J. D., \& Smaldino, S.E. 2002. Instructional Media and Technology for Learning $\left(7^{\text {th }} e d\right)$. California: Merril.

Henderson, A. J. 2003. The E-Learning Question and Answer Book: A Survival Guide for Trainers and Business Managers. New York: AMACOM

Mayer, R.E. 2009. Multimedia Learning (2nd). New York: Cambridge University Press

Naidu, S. 2006. E-learning: A Guidebook of Principles, Procedures, and Practices. New Delhi: Commonwealth Educational Media Centre for Asia (CEMCA)
Nurmayani, S., Sugiarti, Y., \& Mujdalipah, S. 2017. Application of a Blended Learning Model in Agricultural Vocational High Schools. Jurnal Pendidikan dan Teknologi Kejuruan. 23. 4, 355-361

Prasetyo, A.A., Putro, S. C., Wirawan. I. M. 2016. The Blended Learning Accomplishment of Computer and Network Engineering Expertise Program in Vocational Schools. Jurnal Pendidikan dan Teknologi Kejuruan. 23.2, 130-135

Samad, A. 2009. Metode Penelitian Experimen Semu (quasi-experimental research).

Suratno, J. 2010. Pengembangan dan Penggunaan Sumber Belajar Interaktif Berbasis Komputer dalam Pembelajaran Matematika SMP. Thesis, unpublished, Universitas Negeri Yogyakarta 